\title{
Risk of Sexually Transmitted Infections and HIV in Adolescence
}

\author{
Alfaro AC* \\ Department of Epidemiology and Microbiology, National Institute of Hygiene, Cuba
}

\section{Mini Review \\ Volume 2 Issue 2}

Received Date: November 17, 2020

Published Date: December 08, 2020

DOI: $10.23880 /$ aii-16000128 Institute of Hygiene, Epidemiology and Microbiology, Cuba, Email: albacortes@infomed.sld.cu

\section{Abstract}

Introduction adolescents represent a vulnerable group exposed to sexually transmitted infections including HIV/AIDS. It is a stage in which they are subjected to constant changes in physical, mental and social development and risk factors such as ignorance, early sex, drug addiction, social inequality, gender and myths contribute to this exposure.

Objective: To delve into the characteristics of adolescents that put them at risk of acquiring an STI-HIV/AIDS.

Methods: A bibliographic review was carried out where the databases included in the LILACS, EBSCO and HINARI services were consulted, and very good coverage was achieved, both in Cuba, Latin America and the Caribbean, and in the rest of the world.

Conclusions: This review article on the risks to which adolescents are subjected to acquiring an STI-HIV/AIDS is put in the hands of all personnel involved in working with adolescents. For the family doctor in particular for being a staff closely linked to the community, allowing them to be in better conditions to detect these behaviors thus contributing to exercise and undertake prevention actions that will allow us to achieve the objectives of our Ministry of Public Health in relation to with this indicator.

Keywords: HIV/AIDS; Sexually Transmitted Infection; Ministry of Public Health

Abbreviations: WHO: World Health Organization; HIV: Human Immunodeficiency Virus; UNICEF: United Nations Children's Fund; STIs: Sexually Transmitted Infections; CSE: Comprehensive Sexuality Education.

\section{Introduction}

The World Health Organization (WHO) reports that more than two million adolescents between 10 and 19 years old live with the human immunodeficiency virus (HIV), figures that show that the number of infected increased by a third in the last decade, a phenomenon that is due to the lack of education programs on the subject aimed at this age group since they do not receive the care or support they need and that sometimes they do not even know their status as infected, which is why millions more adolescents are at risk of infection [1,2]. The entity proposed a guide to face this situation based on advice, including recommendations to governments to review their laws to make it easier for young people to obtain HIV tests without the need for parental consent, as well as the importance of creating health services in improving the quality of care and social support for those infected and the international community has made the commitment to end the AIDS epidemic by 2030 as a threat to public health $[3,4]$. Mortality rates among adolescents with HIV are not decreasing to the same extent as in other population groups. Although the total number of HIV-related deaths fell by $30 \%$ between 2005 and 2012, deaths from the virus among adolescents increased by $50 \%$ during the same period. One approach that has been particularly successful is that HIV treatment and care services are accompanied by additional support specifically for adolescents [5,6]. A recent 
study in Zimbabwe found that out of 1,776 young people receiving treatment under such a program, they were no longer more likely than adults to die from HIV-related causes, contrary to the general trend in Southern Africa and all over the world [7].

In the Sustainable Development Goals (SDG) of the 2030 agenda, numbers 3, 4 and 5 emphasize the protection of human rights and the promotion with gender equality and the empowerment of women and girls, being considered of vital importance the preservation of sexual and reproductive health. For this, a quality, inclusive and equal education is required [8].

The Ministries of Education and Public Health, in support of the guidelines directed by the World Health Organization (WHO) and the United Nations Children's Fund (UNICEF), have set as their goal the comprehensive training of new generations by creating methodological guidelines for this purpose [9-11]. Resolutions such as Ministerial Resolution 139/2011 with curricular involvement have been drawn up by the Ministry of Education to strengthen issues for the prevention of Sexually Transmitted Infections (STIs), early pregnancy, self-care, taking into account the rights sexuality, gender equality with it is about forming adequate basic values for a responsible social and social behavior [12].

\section{Methods}

To carry out this review and provide readers with an update on the subject in question, the databases included in the LILACS, EBSCO and HINARI services were consulted and very good coverage was achieved, both in Cuba, Latin America and the Caribbean, and in the rest of the world. Web sites on the Internet that must be consulted were also visited for their prestige and leadership on the subject.

The terms were used: adolescence, sexually transmitted infections that include HIV/AIDS, vulnerability and risk in adolescence, the need for sexuality education, educational measures, among others. To support this research work, a theoretical review has been carried out, collecting different aspects related to the importance of sexuality education at this stage of life. For the development of the search strategies, the DeCS controlled language was consulted and the corresponding Boolean operators were included. The documents corresponding to the period 1992-2020 were selected given the importance of the subject discussed.

\section{Development}

Adolescence is a stage defined by the WHO as the period of life that elapses between 10 and 19 years of age. Welldefined stage of the human life cycle between childhood and adulthood characterized by profound biological, psychological and social changes. It is a stage in which social interests appear and feelings never experienced before flourish, which together with the physiological changes make evident a significant transformation in this subject who gradually ceases to be a child [13].

It is a time of continuous bio psychosocial changes, where it is sought to strengthen the personality and the roles that will develop in society. It is considered a period of human development in which an important decision-making process of the subject begins with respect to himself; it is also the beginning of the transition to adulthood. The adolescent often faces, without possessing the necessary psychological resources, the problem of beginning to outline the paths to follow, in order to fully incorporate him into society, which is why his projection of life and his position within it change [14-17].

The adolescent's own characteristics include a lack of impulse control, emotional ambivalence, emotional and behavioral changes, as well as their increasingly early sexual maturation, leading them to seek sexual relations as the beginning of their life active sexual. These characteristics condition them to maintain risky behaviors and expose them to being common victims of Sexually Transmitted Infections (STIs), which is aggravated by the lack of real knowledge about them [5].

Studies indicate that when analyzing the criteria and behavior of adolescents, a high number consider STIs to be shameful and immoral diseases, this will be of great future importance as it negatively influences the search for specialized help if necessary. For the female sex, suffering from an STI is, many times, a factor of humiliation and shame, while for the male sex it is a sign of virility and sexual potency, constituting an alarm sign to consider.

At present there is a tendency to start sexual relations at an earlier and earlier age. Cortés in his study on Sexual behavior and sexually transmitted diseases in adolescents from Basic Secondary School of Ciudad de la Habana, in the ages whose ages were between 11 and 15 years, the highest percentages of initiation of sexual relations were between 12-13 years, with a predominance of males [18].

The demographic and health survey of women carried out in Central and South America indicates that high percentages of adolescents in Mexico, Guatemala, Ecuador, Salvador and Brazil had their first sexual relations before the age of $[15,19]$. It is worrying that at such early ages (911 years) the percentage who reported sexual intercourse even exceeded the ages of 14-15 years, these being the predominant initiation ages in other studies and a greater 
number of sexual partners than results in risk factors for the development of STIs $[20,21]$.

Adolescents respond poorly to types of thinking that require looking to the future to visualize the results of their actions, a characteristic that evaluates the ability to take risks and that arises between 15 and 18 years of age [22]. Adolescents are especially vulnerable to STI-HIV/AIDS since they are in a period of transition in which they are no longer children but have not reached adulthood, their social, emotional and psychological development is incomplete, and they tend to experiment with dangerous forms of behavior, often without realizing the danger. On the other hand, most young people have only limited knowledge of HIV/ AIDS, largely because society does not facilitate obtaining information. Social policies often reveal intolerance and discrimination against youth, such as when they limit access to and care for health information. Public health responses to the needs of these adolescents are often contradictory and misleading. Likewise, social norms and expectations, along with the opinion of adolescents, have a powerful influence on their behavior, generally in such a way that they contribute to increasing health risks.

Adolescents who deny their personal risk of contracting HIV/AIDS may ignore prevention messages, dismiss their importance, or think that they are not responsible for protection. Risky behaviors can be sexual or social and the combination of both is frequent and very dangerous for sexual and reproductive health, which is why adolescence is considered a vulnerable group. The main consequence of risky sexual behavior is framed in reproductive damage, with the presence of an increase in early pregnancies, abortions and sexually transmitted infections (STIs) and that in turn is related to the social behaviors of risk unfortunately can culminate in the frustration of the life project.

It is important to note that the changes that occur at the brain level that would explain risk behaviors and specific social behaviors during this stage are of great importance, so that said behaviors, emotions, social relationships, the way of thinking, will also undergo spectacular transformations during this stage of adolescence [22,23]. We are obliged to think about adolescence to prevent responsibly. The formula is that Comprehensive Sexuality Education (CSE) is needed, thus favoring responsible sexuality and also remember that this is a stage in which relationships with peers are very significant.

The Cuban curricular educational conception assumes the process of sexuality education with a gender and sexual rights approach from a comprehensive, transversal perspective that promotes an active educational process. We conclude that it is necessary to develop skills through knowledge that allows assertive dialogue with adolescents in the prevention of sexually transmitted infections-HIV/AIDS, preventing responsibly.

\section{References}

1. (2020) Fact Sheet Latest statistics on the status of the AIDS Epidemic. Onusida.

2. (2018) National Center for Information on Medical Sciences, National Medical Library: HIV AIDS. World Statistics, pp: 13.

3. Cortes Alfaro A, Soto RO, Medina RS, Latero Abreu MI, Joanes JJF (2019) HIV Infection in Adolescents in Cuba, 1987 to 2018. An Epidemiological Approach. Acta Scientific Microbiology 2(11): 130-137.

4. (2013) Coping with HIV in adolescence. World Health Organization.

5. Cortés Alfaro A, García Roche R, Fullerat Alfonso R, Fuentes Abreu J (2000) Work instrument for the study of sexually transmitted diseases and HIV/AIDS in adolescents. Rev Cuban Med Trop 52(1): 48-54.

6. Draft final document of the United Nations summit for the approval of the post-2015 development agenda. PAHO/WHO.

7. (2018) WHO Recommendations on Adolescent Sexual and Reproductive Health and Rights. World Health Orignization.

8. Cortés Alfaro A, García Roché R, Duque Santana I, Ochoa Soto R, Aguilar Valdés J (2006) Methodology for the prevention of STI-HIV/AIDS in adolescents and young people. National Center for STI/HIV/AIDS Prevention.

9. Torres Cueto MA, Roca Zayas AA, Delgado EC, Hernández AG, Gómez ABL, et al. (2011) Sexuality education and prevention of STIs and HIV/AIDS from the gender, rights and sociocultural perspectives. Basic secondary education, pre-university, professional and adult technique. Havana: Ministry of Education, pp: 109.

10. (2012) Sexuality Education Program with a Gender and Sexual Rights Approach in the national education system. Ministerial Resolution No: 139/2011. Ministry of Education, Havana

11. Hernández Machín LE, Malo Gutiérrez MNH, Ruz Hernández Y, Cabrera Sánchez Y, Míreles Hernández OM (2014) Evaluation of the level of knowledge of young adolescents about sexuality. Rev Medical Sciences 18(1): 33-44. 
12. Cruz Sánchez F, Rodríguez Alonso B, Alonso Uría RU (2014) Childcare in adolescence. Havana: Ministry of Public Health, pp: 16.

13. Borrego GN, Pérez Enríquez M (2016) Comprehensive education of sexuality in childhood, adolescence and youth. Conceptual approach. In: Guerrero Borrego N (Eds.), Reflections and views on sexuality in childhood, adolescence and youth. Havana: CENESEX, pp: 21.

14. (2015) World Population Prospects. ONEI Life Expectancy at Birth 2011-2013.

15. Gretter Anaudina RR, Ayes Claudia CB, Laura DG (2016) We are equal? Characterization of racial identity in a group of adolescents from Havana. Journal of the Cuban Institute for Cultural Research, pp: 3-18.

16. Roche R, Fuentes Abreu J (2000) Sexual behavior and sexually transmitted diseases in secondary school adolescents. Rev Cubana Hig Epidemiol 38(1).

17. (1995) The health of adolescents and young people. Social situation of adolescents and young people in Latin America. Geneva: PAHO/ WHO, pp: 70-83.
18. Rodríguez DP, Ripol S (1992) Early motherhood and some psychosocial and psycho environmental aspects. Rev Cub Obst and Ginecol 8(3): 285-293.

19. (1995) The health of adolescents and youth in the Americas: writing to the future. World Health Organization.

20. Guerrero Borrego N, Pérez Enríquez M (2016) Education Comprehensive sexuality in childhood, adolescence and youth. Conceptual approach. In: Borrego GN (Eds.), Reflections and views on sexuality in childhood, adolescence and youth, pp: 21 .

21. (2016) Why is Comprehensive Sexuality Education important. UNESCO.

22. González Bango MA (2018) Education in sexually transmitted infections from early adolescence: unquestionable need. Rev Med Electron 40(3).

23. Roca Zayas AA (2015) Comprehensive Sexuality Education with a gender and law approach in the educational system. Ministry of Education Havana. 